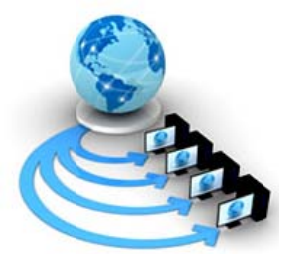

Volume 9, No. 1, January-February 2018

International Journal of Advanced Research in Computer Science

RESEARCH PAPER

\author{
Available Online at www.ijarcs.info
}

\title{
A TABLEAU TOOL FOR AN BRANDING BUILDS FINANCIAL VALUE THROUGH YOUR APPEARANCE AND STYLE
}

\author{
M.Anusha, Y.Swathi, P.Deepika, P.Sravya \\ III/IV B.Tech, Department of IT, PVPSIT \\ Vijayawada, India
}

\author{
R.Vijaya Kumar Reddy \\ Assistant Professor, Department of IT, PVPSIT \\ Vijayawada, India
}

\author{
K. Prudvi Raju, G. Venugopal \\ Assistant Professors, Department of IT, PVPSIT \\ Vijayawada, India
}

\begin{abstract}
Highlighting of a man, recognizes an association or item depends on the mark. The Thing that how we immediately perceived by world depends on our image of material and gems. The Financial Value is getting through your appearance and style before the world. Marking starts things out in showcasing correspondence and nobody would not have any desire to be without it. New Looks affirms your being straightforward and having solid good standards before the world. Marking technique is utilized to grandstand your item to the shoppers by showcasing it. Business or association are given significance by considering if it is uncountable arrangements. In Business destinations, one can understand the motivation behind Brand serves which was a guide. The specialist to adjust a promoting plan with those destinations by you and satisfy the far-reaching an arrangement of activity. The adequacy of marking need not occur simply getting it, but rather one ought to likewise involvement in life how brand ought to achieve it to a customer. Get this Ultimate in addition to the application and you a character our image esteem and rating that world given.
\end{abstract}

Keywords: Highlighting of a man, recognizes an association or item depends on the mark.

\section{INTRODUCTION}

This application is implied forgetting full survey and nature of a brand and store. It contains all the data about brands and where are they benefit from demonstrating specific brands and stores at specific Location in a specific State in view of land portrayal. This information application causes everybody to get ideal thought regarding material wear, devices, form, footwear, sustenance, amusement in our environment. What's more, an insight about the timings, rating and furthermore their contact subtle elements like telephone number, the site for that specific store or it might be at accessible at any shopping center, this gives in which shopping center it is accessible too.

\section{PROPOSED SYSTEM}

The reason for existing is to outline the geological portrayal of the item. It is anything but difficult to distinguish the Store by utilizing a Geographical Location which was connected up in the application is to get undeniable information about a specific place that is picked by a client. It is done of the marking works through information representation instrument.

\section{AdVANCEMENTS USED}

\section{A. MICROSOFT EXCEL}

The Spreadsheet is utilized as a part of Microsoft exceed expectations which is produced by Microsoft for various working frameworks like Windows, macOS, Android and so forth. It is utilized for computation, charting, rotate tables by taking the qualities of the cells and large-scale programming dialect with Visual Basic for Applications. Microsoft exceeds expectations spreadsheet is utilized to accumulate the information and Visual Basic for Applications (VBA) is utilized for programming bolsters, which is a dialect of Visual Basic. Visual Basic for Applications permits spreadsheet task that is troublesome or awkward with ordinary spreadsheet strategies. PC administrator may comprise source code transparently utilizing the Visual Basic Editor (VBE), which incorporates source code composing instrument, troubleshooting of code and module association condition. we can likewise utilize Microsoft exceed expectations for measurable information additionally [1],[6].

\section{B. MICROSOFT TABLUEA}

The Scene is an information perception device which is seen by numerous orders as a present innovation of visual correspondence. It additionally has a mapping usefulness and can plot scope and longitude coordinates. Information can be created and learned of the visual portrayal. Convey data plainly and productively through factual illustrations, plots and data designs utilizing information perception Tableau [2],[5],[6].

\section{DASHBOARD}

Different worksheets are assembling under a dashboard and partner data has appeared in a specific place, simultaneously we can look at and screen an assortment of information. For instance, you may have an arrangement of perspectives that you audit each day. A dashboard shows 
every one of the perspectives on the double, rather than flipping through every worksheet that is made by you. [2], [5].

\section{FILE}

A scene record can be made utilizing new choices and load all the required traits into it. The scene document with an expansion: .tbsl is utilized to spare a record. Records can be spared in various kinds of information positions.

\section{E. MAPS}

Geologically information can be a picture by utilizing this application; we can plot the information on a guide in Tableau [3], [4],[6].

\section{F.SERVER}

Scene gives three distinct devices to sharing data

- tableau open

- tableau on the web

- tableau server.

It is a cloud-based free facilitated benefit for bloggers, understudies or information perception supporters that need to share the work transparently. The Server can be introduced on equipment behind your firewall or on cloud benefits that you contract with specifically [2],[5].

\section{G. APPS}

4. IN THIS APPLICATIONS, VERSATILE CLIENTS CAN WITHOUT MUCH OF A STRETCH INVESTIGATE AND OFFER SUBSTANCE DISTRIBUTED TO SCENE ON THE WEB OR SCENE SERVER. THIS APPLICATION YOU WILL DISCOVER THERE IS PERFECT WITH EVERY SINGLE BOLSTERED RENDITION OF SCENE SERVER.

\section{4. RESULTS}

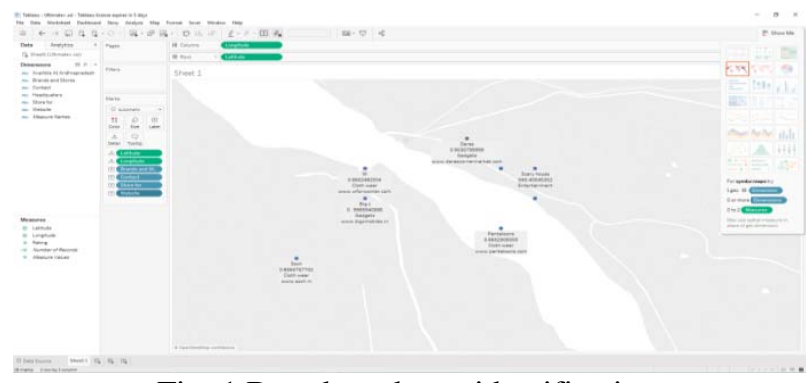

Fig: 1.Brand products identification

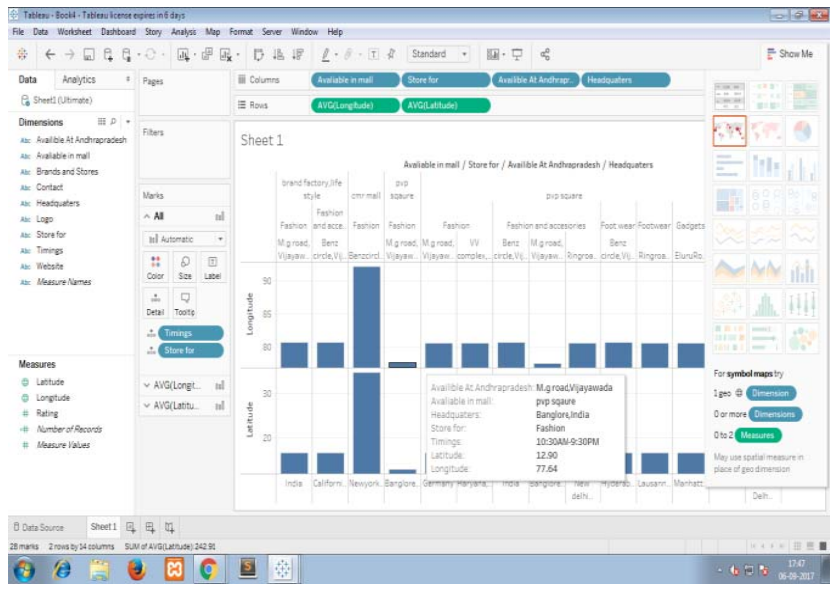

Fig:1.2 Brand products Representation in Tableau
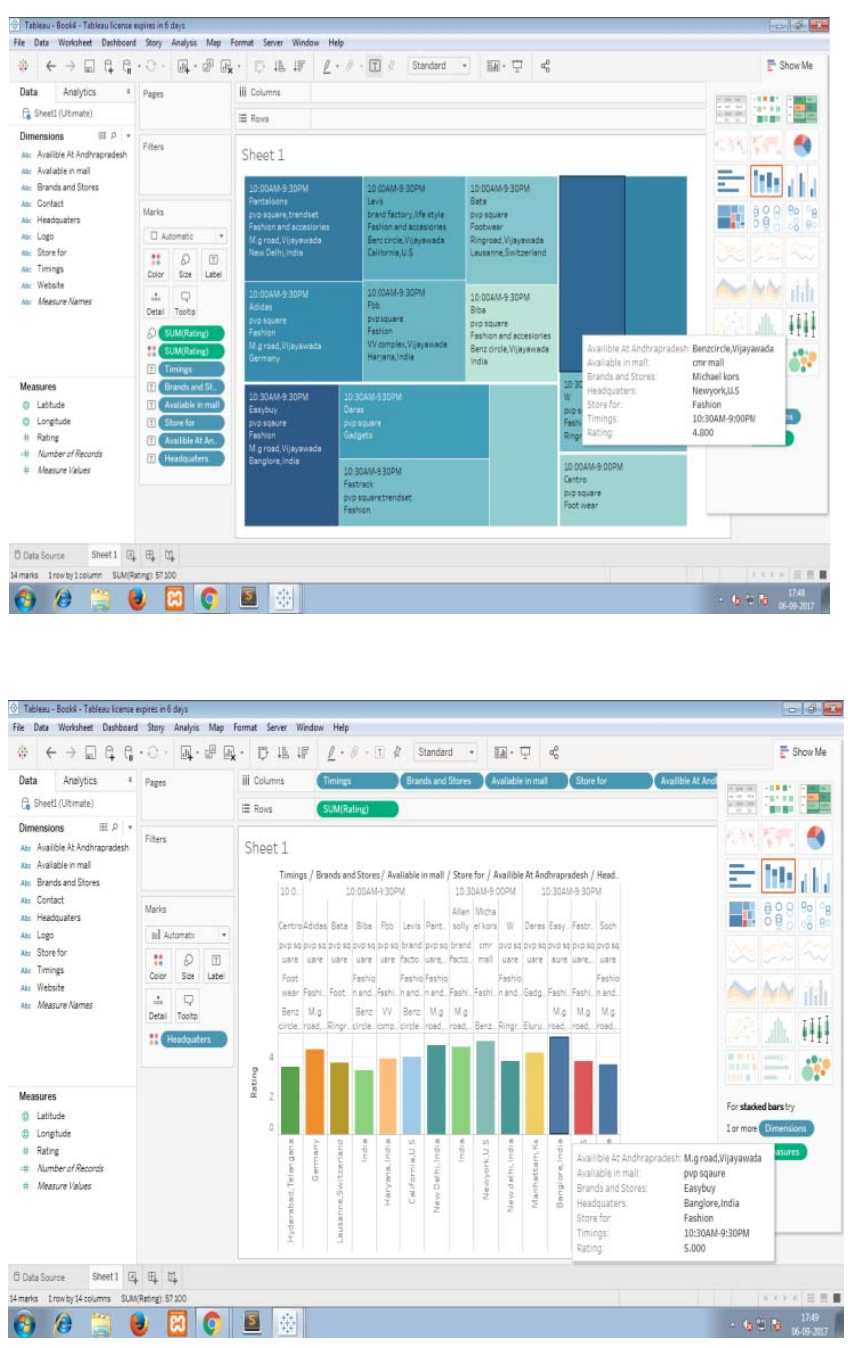

Fig: 2.1, 2.2 Details of a Particular brand products 


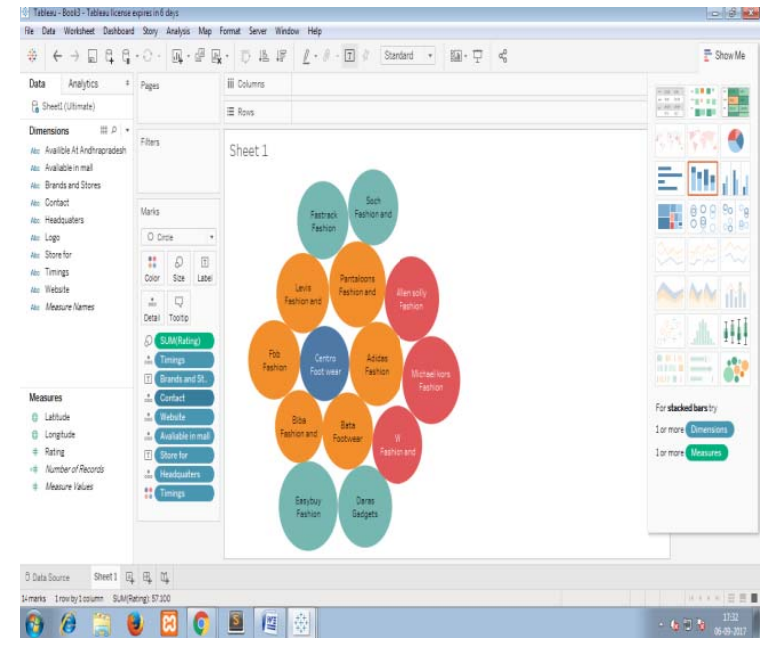

Fig:3Dashboard representing brand products according to their rating

\section{CONCLUSION}

Therefore we have imagined the information i.e about different brand items accessible in Vijayawada. It additionally has future upgrades like, we can cross our boundaries and move to a different locale, at that point states, at that point nations et cetera.

\section{REFERENCES}

[1] https://www.tutorialspoint.com/excel/

[2] https://community.tableau.com/community/viz-talk/tableaucommunity-library/twl

[3] https://www.timeanddate.com/geography/longitude-latitude.html

[4] https://www.latlong.net/

[5] Pat Hanrahan, Christian Chabot, Chris Stolte.”Tableau Software" https://www.tableau.com/products/desktop

[6] Ch. Likhitha, International Journal of Modern Sciences and Engineering Technology (IJMSET) ISSN 2349-3755; Available at https://www.ijmset.com Volume 4, Issue 5, 2017, pp.1-5 